and sludge from wet river beds but only rarely from healthy persons. ${ }^{4}$ The infection is reported rarely in Britain and during 198124 isolations from cases of diarrhoea were recorded by Communicable Disease Surveillance Centre (personal communication). It is, however, possible to overlook the presence of the organism if identification is orientated to recognition of the known pathogens from deoxycholate citrate agar-that is, Shigella and Salmonella. The organism being a late lactose fermenter may, under those circumstances, not be processed. If the Analytical Profile Index $10 \mathrm{~S}$ system is used for identification, a preliminary oxidase test must be carried out otherwise the organism may be wrongly identified as Escherichia coli.

The pathogenetic mechanism of $P$ shigelloides in humans has not yet been defined. Production of a heat-stable enterotoxin has recently been reported from India. ${ }^{5}$ The present case indicates its invasive ability, and $P$ shigelloides should be added to the growing list of organisms able to produce acute colitis.

${ }^{1}$ Rahman AFM, Willoughby JMT. Dysentery-like syndrome associated with Aeromonas hydrophila. Br Med f 1980;281:976.

${ }^{2}$ Mandal BK, Schofield PF, Morson BC. A clinico-pathological study of acute colitis: the dilemma of transient colitis syndrome. Scand $\mathcal{F}$ Gastroenterol 1982;17:865-9.

${ }^{3}$ Ferguson WW, Henderson ND. Description of Strain C27: a motile organism wich the major antigen of Shigella sonnei phase I. $f$ Bacteriol 1947;54:179-81.

- Arai T, Ikejima N, Itoh T, Sakai S, Shimeda T, Sakazaki R. A survey of Plesiomonas shigelloides from aquatic environments, domestic animals, pets and humans. 7 Hyg (Lond) 1980 ;84:203-11.

${ }^{5}$ Sanyal SC, Saraswathi B, Sharman P. Enteropathogenicity of Plesiomonas shigelloides. $\mathcal{F}$ Med Microbiol 1980;13:401-9.

(Accepted 21 September 1982)

Regional Department of Infectious Diseases and Department of Microbiology, Monsall Hospital, Manchester M10 8WR

B K MANDAL, FRCP, consultant physician

K WHALE, MRCPATH, consultant microbiologist

Department of Pathology, St Mark's Hospital, London

B C MORSON, FRCPATH, consultant pathologist

\section{Accuracy of early endoscopy in acute upper gastrointestinal bleeding}

The accuracy of early endoscopy in acute upper gastrointestinal haemorrhage has been established mainly with reference to the results of barium meal examination. ${ }^{1}$ In small series, comparison of findings at endoscopy with those at surgery or necropsy has suggested that endoscopy may miss up to $8 \%$ of peptic ulcers. ${ }^{2-5}$ We compared the findings at endoscopy in patients with acute upper gastrointestinal bleeding with those at surgery or necropsy, as this has not been reported previously.

\section{Patients, methods, and results}

A total of $104(34 \%)$ of 308 consecutive patients referred for early endoscopy for acute upper gastrointestinal bleeding came to surgery (99) or necropsy alone (5). The endoscopies were performed by 11 endoscopists of varying experience, though all had sufficient experience to perform endoscopy without direct supervision and all had access to help from more experienced endoscopists. All endoscopies were performed with end-viewing instruments; side-viewing instruments were also used occasionally.

The main bleeding lesions in the 104 patients $(65$ men, 39 women aged 16-88 (mean 58) years) were duodenal ulcers (41), gastric ulcers (28), and oesophageal varices (16). Gastric erosions, gastric carcinoma, jejunal ulceration, and Mallory-Weiss tears accounted for the remaining lesions. Endoscopy correctly identified the bleeding lesion in $76(73 \%)$ patients. The sites of bleeding were identified correctly in a further 12 patients but the lesions causing the bleeding (nine duodenal ulcers, one gastric carcinoma, one gastric ulcer, and one Mallory-Weiss tear) could not be seen. Lesions were misinterpreted in two cases; a gastric ulcer proved to be a gastric carcinoma, and an erosion was found at operation to be an acute gastric ulcer. Blood prevented an adequate examination in three patients found subsequently to be bleeding from chronic gastric ulcers. Endoscopy gave incorrect findings in 11 cases (see table). Five of the gastric ulcers $(18 \%)$ were misdiagnosed, one $(4 \%)$ was not seen, though the site of bleeding was identified, while in three $(11 \%)$ the sites were obscured by bleeding. Five of the duodenal ulcers $(12 \%)$ were misdiagnosed and nine $(22 \%)$ were not seen, though the sites of bleeding were identified.

Lesions diagnosed incorrectly at endoscopy

\begin{tabular}{ll}
\hline Final diagnosis* & Diagnosis at endoscopy \\
\hline Gastric erosions & Gastric ulcer \\
Gastric ulcer & No lesion found \\
Gastric ulcer & No lesion found \\
Gastric ulcer & Gastric erosions \\
Gastric ulcer & Haemorrhagic gastritis \\
Gastric ulcer & Duodenal bleeding \\
Duodenal ulcer & No lesion found \\
Duodenal ulcer & Gastric bleeding \\
Duodenal ulcer & Antral lesion (?carcinoma) \\
Duodenal ulcer & Bleeding from gastrojejunal anastomosis \\
Duodenal ulcer & Antral ulcer (bleeding) and duodenal ulcer \\
\hline
\end{tabular}

*At surgery, necropsy, or both.

\section{Comment}

Endoscopy identified the bleeding site or the bleeding lesion correctly in $85 \%$ of our patients, and in a further two patients the errors could not be regarded as serious, for benign and malignant gastric ulcers, and gastric erosions and acute gastric ulcers cannot be differentiated reliably at endoscopy. Severe bleeding prevented adequate examination in three cases $(3 \%)$, which is consistent with previous experience. ${ }^{3}$ Our failure to diagnose $18 \%$ of gastric ulcers and $12 \%$ of duodenal ulcers suggests that early endoscopy for gastrointestinal bleeding may not be as accurate as previously supposed. Most of the endoscopies were performed with older, less flexible panendoscopes, which made retrograde examination of the stomach difficult; some of the gastric lesions might have been seen if a more modern panendoscope had been used. We think it unlikely, however, that newer panendoscopes would have given a higher yield in the duodenal cap.

There is no way of knowing what effect our mistakes had on the management of patients. It is unlikely that operation was delayed where bleeding was thought to be coming from a specific site or lesion (table, five patients) or with recurrent or continued bleeding with a negative finding at endoscopy (three patients). Continued conservative treatment could have resulted from incorrect diagnoses of gastritis or erosions (two patients), and an unnecessary operation could have resulted from diagnosing a gastric ulcer rather than erosions (one patient). It seems likely, therefore, that management would have been altered greatly in only three of the 11 patients in whom a clear diagnostic error was made; these three representing only $3 \%$ of the whole series.

In practical terms our study indicates that patients should undergo a second endoscopy after an inadequate endoscopy if bleeding recurs and surgery is contemplated or if the findings seem inappropriate to the patient's clinical state and that patients with considerable amounts of blood in their stomach are likely to require urgent surgery.

Correspondence should be addressed to JAHF.

${ }^{1}$ Stevenson GW, Cox RR, Roberts CJC. Prospective comparison of doublecontrast barium meal examination and fibreoptic endoscopy in acute upper gastrointestinal haemorrhage. $\mathrm{Br} \mathrm{Med} \mathcal{F} 1976$;ii :23-4.

${ }^{2}$ Cotton PB, Rosenberg MT, Waldram RPL, Axon ATR. Early endoscopy of oesophagus, stomach and duodenal bulb in patients with haematemesis and melaena. Br Med f 1973; ii :505-9.

${ }^{3}$ Forrest JAH, Finlayson NDC, Shearman DJC. Endoscopy in gastrointestinal bleeding. Lancet 1974 ;i : 394-7.

${ }^{4}$ McGinn FP, Guyer PB, Wilken BJ, Steer HW. A prospective comparative trial between early endoscopy and radiology in acute upper gastrointestinal haemorrhage. Gut 1975;16:707-13.

Dronfield MW, McIllmurray MB, Ferguson R, Atkinson M, Langman MHS. A prospective randomised study of endoscopy and radiology in acute upper gastrointestinal-tract bleeding. Lancet 1977;ii:1167-9.

(Accepted 21 September 1982)

Gastrointestinal and Liver Service, Royal Infirmary, Edinburgh EH3 9YW

C ZAMBARTAS, MRCP, medical registrar (now: senior medical registrar, Limassol General Hospital, Limassol, Cyprus)

R J CREGEEN, MRCP, medical registrar

J A H FORREST, $M D, M R C P$, senior registrar in gastroenterology (now: consultant physician, Stobhill General Hospital, Glasgow G21 3UW) N D C FINLAYSON, PHD, FRCPE, consultant physician 